\title{
Investigating arbuscular mycorrhizal fungal infection in medicinal plant roots in different localities of tehsil Shabqadar, district Charsadda, and Khyber Pakhtunkhwa Province, Pakistan
}

\author{
Tabassum Yaseen ${ }^{1 *}$, Farah Mabood ${ }^{1}$, Rani Gul$^{2}$, Kushnood Ur Rehman ${ }^{3}$ \\ and Naveed Akhtar ${ }^{3}$ \\ 1. Department of Botany, Bacha Khan University Charsadda Khyber Pakhtunkhwa Province-Pakistan \\ 2. Department of Agriculture, Bacha Khan University Charsadda Khyber Pakhtunkhwa Province-Pakistan \\ 3. Department of Botany, Islamia Collage Peshawar Khyber Pakhtunkhwa Province-Pakistan \\ *Corresponding author's email: sciences111@yahoo.com,tabassumyaseen@bkuc.edu.pk \\ Citation \\ Tabassum Yaseen, Farah Mabood1, Rani Gul, Kushnood Ur Rehman and Naveed Akhtar. Investigating arbuscular \\ mycorrhizal fungal infection in medicinal plant roots in different localities of tehsil Shabqadar, district Charsadda, \\ and Khyber Pakhtunkhwa Province, Pakistan. Pure and Applied Biology. Vol. 9, Issue 1, pp427-435. \\ http://dx.doi.org/10.19045/bspab.2020.90046
}

Received: 22/07/2019 Revised: 19/09/2019 Accepted: 07/11/2019

Online First: 15/11/2019

\section{Abstract}

Arbuscular mycorrhiza represents plant-fungal association in which fungal partner gets carbohydrates and improves the nutrient uptake of host plants enhancing plant growth and productivity. The present work was done with the aim of generating baseline information on Arbuscular mycorrhizal fungi (AMF) in medicinal plants of different locations of Tehsil Shabqadar, District Charsadda, Khyber Pukhtunkhwa Pakistan. During the study, total of 40 medicinal plants were evaluated at different growth stages (i.e. vegetative, fruiting, and flowering) for investigating the AMF root colonization. During the study, high root colonization (95-100\%) was shown by family Asteraceae, and Meliaceae, and the lowest in families of Libatacea, Solanacea, Lamaceae, Chenopodiaceae and Rhamnaceae respectively (10-20\%). Among the localities, the highest host colonization by AMF was found in village Gonda and Nasratzai (100\%) followed by Village Kangra and Pindi kaly, whereas no colonization/infection was found in Karimo. Similarly, the concentration of sand, silt, clay, organic matter, Calcium etc. determined at all locations studied were also different. As large number of medicinal plants can be found in different Locations of District Charsadda, extensive research work is required to create database of mycorrhizal species colonizing these medicinal plants and to determine their medicinal values for treatment of different infections.

Keywords: Arbuscular mycorrhizal fungi; Medicinal plants; Roots colonization; Shabqadar

\section{Introduction}

Mycorrhiza is symbiotic association between arbuscular mycorrhizal fungi (AMF) and plant roots [1]. This association is found between the majority (80\%) of terrestrial plant species [2]. It can benefit plants through improved nutrients uptake such as phosphorus $(\mathrm{P})$, nitrogen, $(\mathrm{N})$ and zinc $(\mathrm{Zn})$ 
[3-5]. The role of AMF on nutrient uptake (N, $\mathrm{P}, \mathrm{K})$ as well as effect of nutrient intensity on AMF crops has previously been studied [6, 7]. Colonization of AM fungi has negatively been affected by $\mathrm{P}$ and positively affected by $\mathrm{N}$ addition [8]. Colonization of roots by AM fungi improve growth and productivity of several field crops $[9,10]$, increasing uptake of nutrient elements [7]. Medicinal plants may be defined as those plants that are commonly used in treating and preventing specific ailments and diseases and that are generally considered to be harmful to humans [11].

In Pakistan, more than $60 \%$ of the population living in rural areas are not either aware of modern health care facilities or cannot afford it due to which they rely on old health care practices including use of extracts of medicinal plants [12]. Considering the high dependency on medicinal plants, it is suggested to analyze their metal composition, side effects and proximate analysis etc. [13] so that it can be safely administered to patients. These plants species are not only used for medicinal purposes but also been used as food source [13, 14]. To get an overview on AMF infection in the medicinal plants, the present study aims to generate baseline information on Arbuscular mycorrhizal fungi (AMF) in medicinal plants of different locations of Tehsil Shabqadar, District Charsadda, Khyber Pukhtunkhwa Pakistan.

\section{Materials and methods}

Forty samples of plant roots and soil were collected from different areas of District Charsadda during 2015-2016. These areas include Kangra, Nasratzai, Shahganga, Gonda, Yaghyband, Pindi kally, lalma, Shakoor, Bulb kally and Karimo. Plant samples studied belonged to different families, including Nyctaginnaceae (1 specie), Poaceae (2 specie), Lamiaceae (4 species), Cannabaceae (2 species), Amaranthaceae (2 species), Meliaceae (2 species), Solanaceae (6 species), Asteraceae (5 species), Fabaceae (2 species), Chenopodiaceae (1 species), Verbenaceae (3 species), Apiaceae (1 species), Asclepiadaceae (2 species), Marsilaceae (1 specie), Zygophyllaceae (1 specie), Sapindaceae (1 specie), Rhaminaceae (1 specie), Cucurbitaceae (1 specie), Malvaceae (1 specie) and Labitaceae (1 specie).

The plants were carefully dug up along with their rhizosperic soil in triplicate and transported to laboratory in polythene bags. The plant roots were gently washed under tap water to remove soil particles (Table 1).

Assessment of roots colonization was done using the protocol of Phillips and Hayman, $[15,16]$. The power of hydrogen $(\mathrm{pH})$ of soil water suspension was determined using Equipments, power of hydrogen $(\mathrm{pH})$ meter as described by McClean, [17] and electric conductivity of soil samples was measured by EC meter [18]. Texture class of the soil was determined using textural triangle [19]. Organic matter was determined using Walkly-Black method [20].

\section{Results and discussion}

This Study illustrates Arbuscular mycorrhizalfungi infection in roots of medicinal plants from different study sites of District Charsadda. AMF infection in roots of medicinal plant has widely been studied [2127].

In our study, about $85 \%$ AMF infection was seen in plant Mirabilis Jalapa, (Family, Nyctaginaceae) (Table 1, Fig. 1-4) with Mean values of EH $(0 \pm 0)$, IH (16.7 \pm 14.433$)$ A $(40 \pm 0)$ and $(20 \pm 0)$. The present study is in line with study of Sharma and Jha [28] who has investigated Mirabilis jalapa root length with hyphae, root length with arbuscules, root length with vesicles.

In the present study, the highest root colonization was observed in family Asteraceae (100) which is in concordance to previous results [29]. 
In our study, the lowest root colonization was observed in families Labitaceae, Lamiaceae showing $10 \%$ and $15 \%$ colonization respectively. No colonization was observed in non-mycorrhizal plants Chinopodium album which is in agreement to results of Hildebrandt [30]. Although plants have been categorized as mycorrhizal and nonmycorrhizal plants but this classification is not very convincing as several nonmycorrhizal plants have been demonstrated to be colonized by AM fungi [31-33]. Similarly, some mycorrhizal plants also did not get colonized due to unknown reasons. Our results of getting no colonization even in case of mycorrhizal plants has also previously been reported by other researchers [30].

Our results are also in line with those of Karagiannides et al. [34] who also reported the occurrence of mycorrhiza in some members of the family Lamiaceae, Poor roots colonization was noted from family Poaceae (20\%) during the study which is in contrast to study conducted by Olfat and Jalil [35] where highest roots colonization (i.e. 67\%) has been reported from Poaceae. The AMF infection observed from family Fabacea (40\%) during our study is in concordance to those reported by Olfat and Jalil [35] where the infection percentage was $59 \%$. Similarly the high infection reported from families Astereace and Lamiceace during our study is in contrast to these authors who reported nearly $40-50 \%$ infection in these families. The lowest infection reported by their studies are from families Apiaceae and Solanaceae which is in contrast to our study as we have reported high infection percentage from these families. Our results of getting low infection in family Chenopodiaceae does not support the finding of Alejandra et al. [36] who have reported moderate roots infection in their experiment.

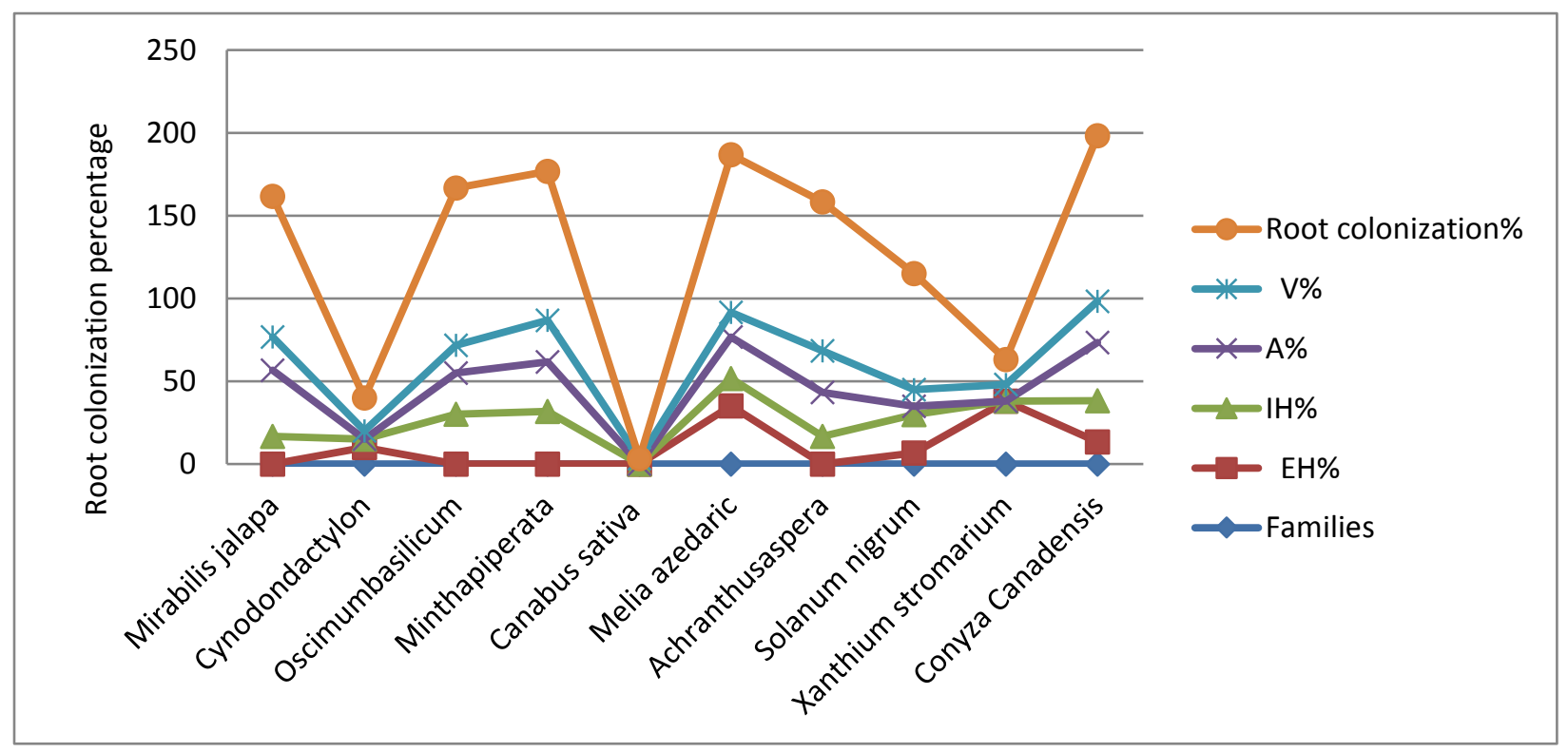

Figure 1. AM fungi detected in different medicinal plants (Mirabilis jalapa, Cynodondactylon, Oscimum basilicum, Minthapiperata, Canabus sativa, MeliaAzedric Acharanthusapera Solinum Nigrum, Xnthium Stromarium, of Shabqadar villages. EH (External hyphae), IH (Internal hyphae), A (Arbuscules), V (Vesicles) 
Yaseen et al.

Table 1. AMF root colonization of different medicinal plants of District Charsadda

\begin{tabular}{|c|c|c|c|c|c|c|c|}
\hline S. No. & Plant species & Families & ЕН\% & IH\% & A \% & $\mathrm{V} \%$ & $\begin{array}{c}\text { Root } \\
\text { colonization } \%\end{array}$ \\
\hline 1 & Mirabilis Jalapa & Nyctaginaceae & $0 \pm 0$ & $16.7 \pm 14.433$ & $40 \pm 0$ & $20 \pm 0$ & 85 \\
\hline 2 & Cynodon dactylon & Poaceae & $10 \pm 0$ & $5 \pm 0$ & $0 \pm 0$ & $5 \pm 0$ & 20 \\
\hline 3 & Ocimum basilicum & Lamiaceae & $0 \pm 0$ & $30 \pm 17.32051$ & $25 \pm 0$ & $16.67 \pm 14.43376$ & 95 \\
\hline 4 & Mintha piperata & Lamiaceae & $0 \pm 0$ & $31.67 \pm 2.8867$ & $30 \pm 0$ & $25 \pm 0$ & 90 \\
\hline 5 & Cannabis sativa & Cannabaceae & $0 \pm 0$ & $0 \pm 0$ & $0 \pm 0$ & $3.33 \pm 5.773503$ & 0 \\
\hline 6 & Melia azedarach & Meliaceae & $35 \pm 0$ & $16.667 \pm 5.773503$ & $25 \pm 0$ & $15 \pm 0$ & 95 \\
\hline 7 & Achranthus aspera & Amaranthaceae & $0 \pm 0$ & $16.667 \pm 5.773503$ & $26.67 \pm 23.094$ & $25 \pm 0$ & 90 \\
\hline 8 & Solanum nigrum & Solanaceae & $6.666 \pm 2.886751$ & $23.3 \pm 2.886751$ & $5 \pm 8.660254$ & $10 \pm 0$ & 70 \\
\hline 9 & Xanthium strumarium & Asteraceae & $38.5 \pm 0$ & $0 \pm 0$ & $0 \pm 0$ & $10 \pm 0$ & 15 \\
\hline 10 & Conyza Canadensis & Asteraceae & $13.3 \pm 2.886751$ & $25 \pm 0$ & $35 \pm 0$ & $25 \pm 0$ & 100 \\
\hline 11 & Acacia concinna & Fabaceae & 6.6672 .886751 & $10 \pm 8.660254$ & $30 \pm 0$ & $35 \pm 0$ & 40 \\
\hline 12 & $\begin{array}{c}\text { Chenopodiaceae } \\
\text { ambrosioides }\end{array}$ & Chinopodiaceae & $0 \pm 0$ & $15 \pm 0$ & $0 \pm 0$ & $0 \pm 0$ & 20 \\
\hline 13 & Pertinum hysteroporus & Asteraceae & $10 \pm 5$ & $15 \pm 0$ & $0 \pm 0$ & $15 \pm 0$ & 60 \\
\hline 14 & Verbiscum Thapsus & Verbenaceae & $15 \pm 10$ & $0 \pm 0$ & $15 \pm 0$ & $25 \pm 0$ & 45 \\
\hline 15 & Chenopodiaceae album & Chinopodiaceae & $0 \pm 0$ & $0 \pm 0$ & $0 \pm 0$ & $0 \pm 0$ & 0 \\
\hline 16 & Verbinia officinalis & Verbenaceae & $1 \pm 0$ & $0 \pm 0$ & $3.33 \pm 2.88675$ & $20 \pm 0$ & 50 \\
\hline 17 & Apium graveolens & Apiaceae & $21.7 \pm 2.886751$ & $18.334 \pm 2.88671$ & $20 \pm 0$ & $0 \pm 0$ & 70 \\
\hline 18 & Datura stramonium, & Solanaceae & $6.67 \pm 2.886751$ & $30 \pm 0$ & $0 \pm 0$ & $15 \pm 0$ & 10 \\
\hline 19 & Calotropis procera & Apocynaceae & $18.3 \pm 7.637626$ & $20 \pm 0$ & $5 \pm 0$ & $45 \pm 0$ & 50 \\
\hline 20 & Marsilea quadrifolia & Marsilaceae & $8.33 \pm 2.886751$ & $10 \pm 8.660254$ & $11.67 \pm 20.207$ & $45 \pm 0$ & 65 \\
\hline 21 & Peganum harmala & Nitrariaceae & $18.33 \pm 2.886751$ & $0 \pm 0$ & $15 \pm 0$ & $25 \pm 0$ & 60 \\
\hline 22 & Calotropis procera & Apocynaceae & $0 \pm 0$ & $0 \pm 0$ & $0 \pm 0$ & $0 \pm 0$ & 0 \\
\hline 23 & Dodonaea visscosa & Sapindaceae & $23.3 \pm 2.886751$ & $18.334 \pm 5.773503$ & $30 \pm 0$ & $0 \pm 0$ & 65 \\
\hline 24 & Rhazya stricta & Apocynaceae & $18.33 \pm 2.886751$ & $15 \pm 0$ & $31.67 \pm 5.77350$ & $16.67 \pm 14.43376$ & 70 \\
\hline 25 & Ziziphus mauritiana & Rhamnaceae & $0 \pm 0$ & $0 \pm 0$ & $0 \pm 0$ & $10 \pm 0$ & 20 \\
\hline 26 & Verbascum thapsus & Scrophulariaceae & $1.667 \pm 2.886751$ & $0 \pm 0$ & $5 \pm 0$ & $5 \pm 8.660254$ & 25 \\
\hline 27 & Acacia concinna & Fabaceae & $0 \pm 0$ & $10 \pm 0$ & $40 \pm 0$ & $45 \pm 0$ & 45 \\
\hline 28 & Solanum surattense. & Solanaceae & $0 \pm 0$ & $0 \pm 0$ & $10 \pm 0$ & $45 \pm 0$ & 55 \\
\hline
\end{tabular}




\begin{tabular}{|c|c|c|c|c|c|c|c|}
\hline 29 & $\begin{array}{c}\text { Momordica } \\
\text { Cochinchinensis }\end{array}$ & Cucurbitaceae & $8.33 \pm 2.886751$ & $30 \pm 7.071068$ & $25 \pm 0$ & $20 \pm 0$ & 85 \\
\hline 30 & Datura stramonium, & Solanaceae & $31.67 \pm 2.886751$ & $15 \pm 7.071068$ & $40 \pm 0$ & $20 \pm 0$ & 85 \\
\hline 31 & Canabis sativa & Cannabaceae & 16.675 .773503 & $20 \pm 0$ & $10 \pm 0$ & $0 \pm 0$ & 40 \\
\hline 32 & $\begin{array}{c}\text { Lycopersicon } \\
\text { esculentum }\end{array}$ & Solanaceae & $0 \pm 0$ & $7.5 \pm 3.535534$ & $5 \pm 0$ & $1.667 \pm 2.886751$ & 25 \\
\hline 33 & Ocimum basilicum & Lamiaceae & $10 \pm 0$ & $10 \pm 0$ & $5 \pm 0$ & $0 \pm 0$ & 15 \\
\hline 34 & Mentha spicata & Lamiaceae & $3.33 \pm 5.773503$ & $0 \pm 0$ & $0 \pm 0$ & $10 \pm 0$ & 20 \\
\hline 35 & Calendula officinalis & Asteraceae & $6.667 \pm 2.886751$ & $0 \pm 0$ & $45 \pm 0$ & $5 \pm 2.886751$ & 55 \\
\hline 36 & Hibiscus esculentum & Malvaceae & $10 \pm 17.32051$ & $0 \pm 0$ & $30 \pm 25.98076$ & $30 \pm 0$ & 75 \\
\hline 37 & Mentha vulgaris & $\begin{array}{c}\text { Lamiaceae or } \\
\text { Labiatae }\end{array}$ & $0 \pm 0$ & $12.5 \pm 3.535534$ & $5 \pm 0$ & $\begin{array}{c}24.667 \pm 21.3619 \\
6\end{array}$ & 10 \\
\hline 38 & Melia azedarach & Meliaceae & $13.34 \pm 2.88675$ & $7.5 \pm 10.6066$ & $30 \pm 0$ & $0 \pm 0$ & 45 \\
\hline 39 & Capsicum annuum & Solanaceae & $1.667 \pm 2.88675$ & $0 \pm 0$ & $0 \pm 0$ & $35 \pm 0$ & 40 \\
\hline 40 & Carthamus oxyacantha & Asteraceae & $0 \pm 0$ & $0 \pm 0$ & $0 \pm 0$ & $0 \pm 0$ & 0 \\
\hline
\end{tabular}

Key: EH (External hyphae), IH (Internal hyphae), A (Arbuscules), V (Vesicles) 


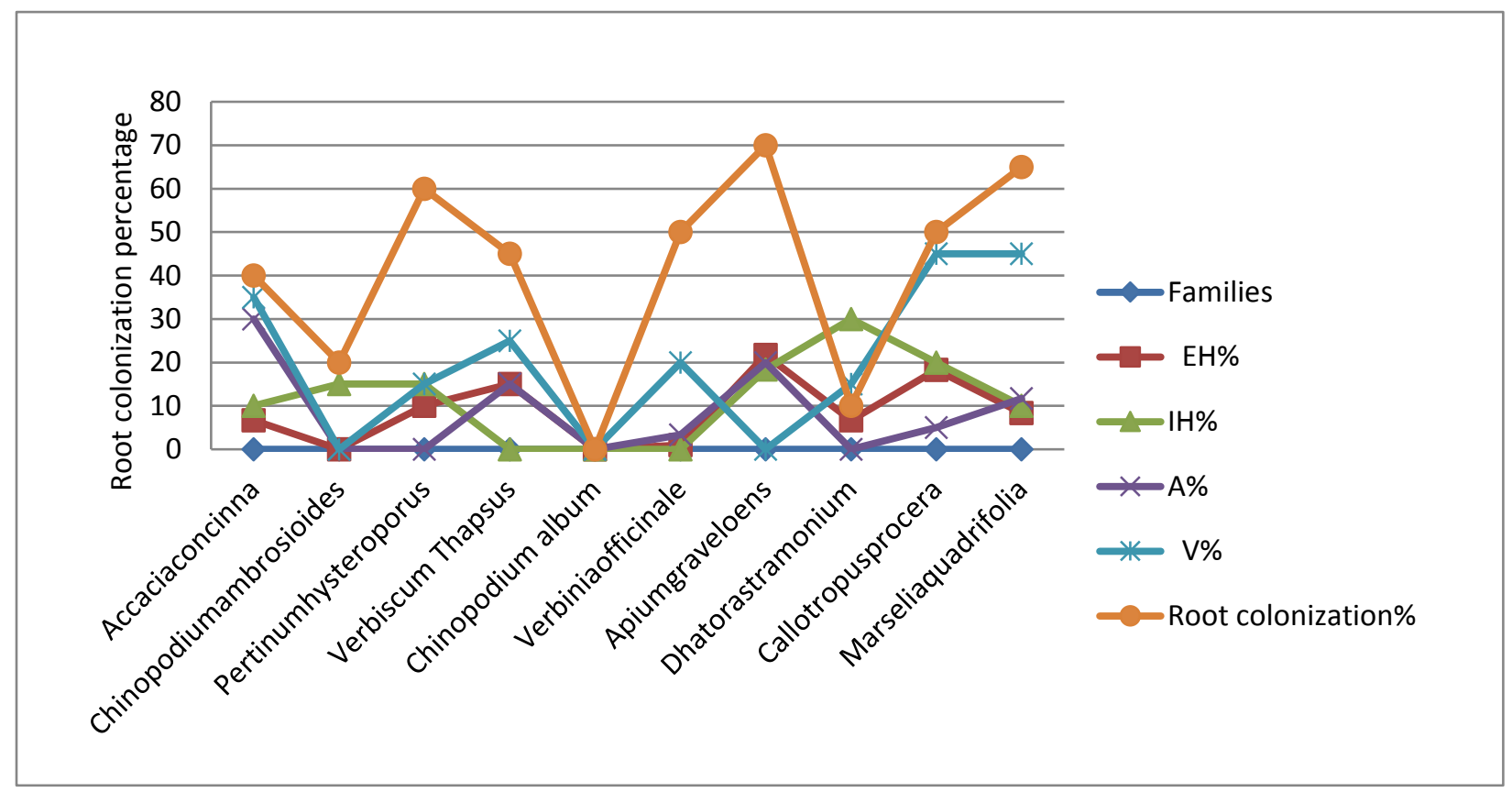

Figure 2. AM fungi detected in Different medicinal plants (Accaciacoincina, Chenopodiaceae ambriosiods, Pertinum hysteroporus, Verbescum Thapsus, Chenopodiaceae album, Verbena officinale, EH (External hyphae), IH (Internal hyphae), A (Arbuscules), V (Vesicles) apigravelones, Dhatora stramonium, callotropus procera, marseliaquadrafolia

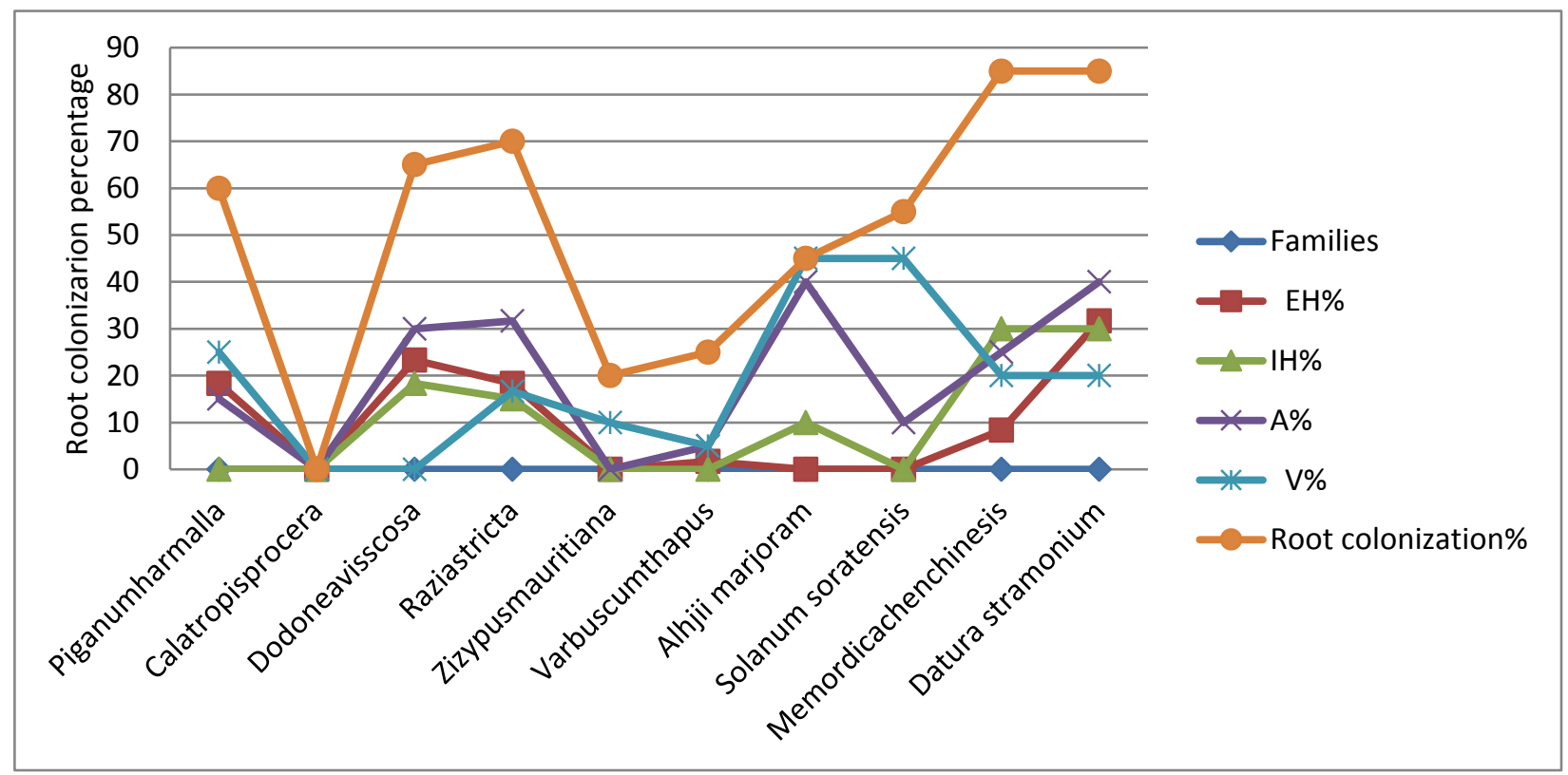

Figure 3. AM fungi detected in Different medicinal plants (Piganumharmalla, Calotropas procera, Dodonea visscosa, Raziastratica, Zizipus muratiana, Verbescum Thapsus, Alhjii marjoram, Solanum soratense, Memordicachenchinensis, Dhatora stramonium). EH (External hyphae), IH (Internal hyphae), A (Arbuscules), V (Vesicles) 


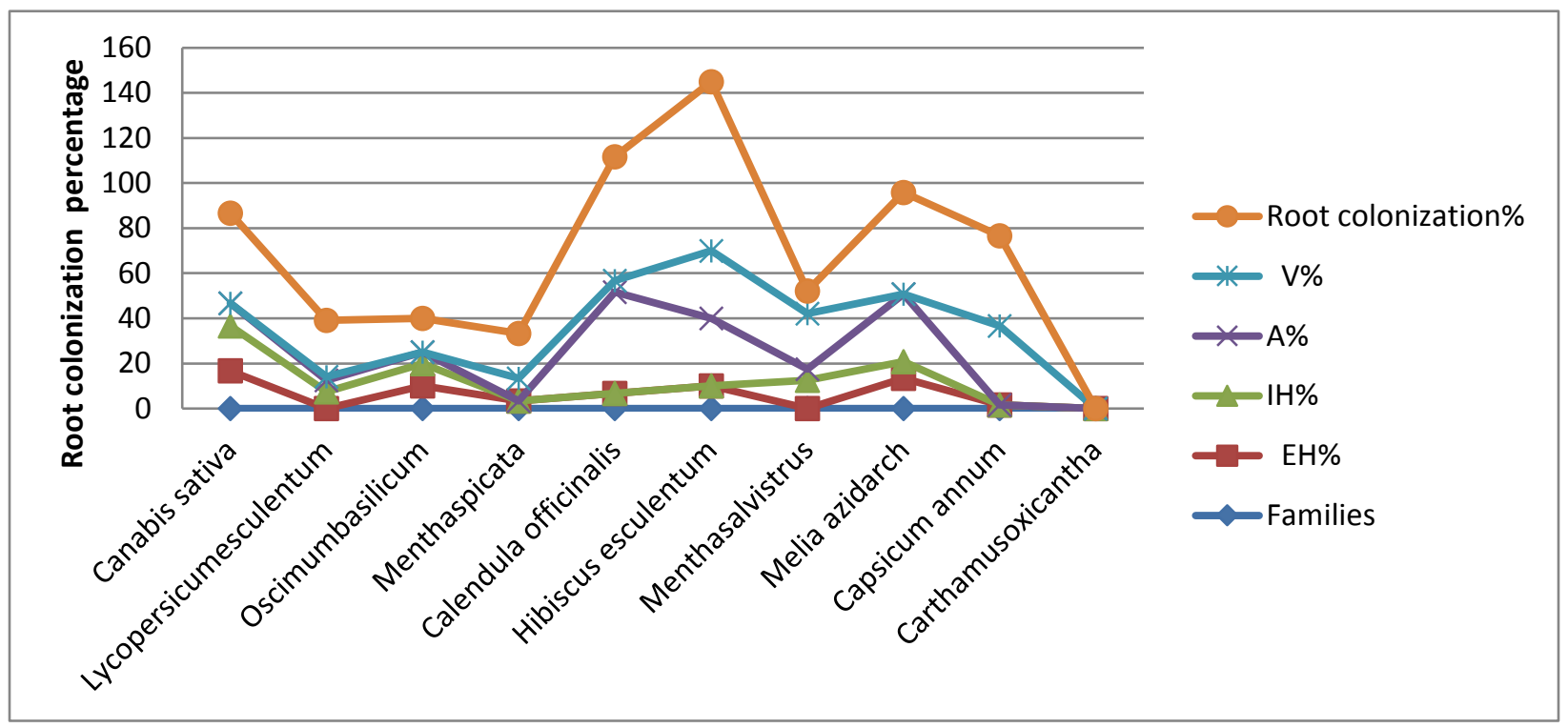

Figure 4. AM fungi in Different medicinal plants (Canabus sativa, Lycopersicum esculentum, Oscimum basilicum, Menthaspicata, Calendula officinale) (Hibiscus esculentum, Mentha sylestris, Melia azedaric, Carthamus oxicantha). EH (External hyphae), IH (Internal hyphae), A (Arbuscules), V (Vesicles)

\section{Conclusion}

This study confirms that AMF effectively improved the growth of medicinal plant. The growth promotion of medicinal plants depends on the soil mycorrhizal infectivity and functional abilities of soil microorganisms rely on inoculation of AM fungi. Inoculation of field crops with AM fungi can prove an effective practice in improving the production of medicinal plants and also improve the soil bio-functioning. It is also worth thinking to have detailed knowledge of AMF ecology, better fungal strain, adaptability to environmental conditions for getting better yields and sustainability.

\section{Authors' contributions}

Conceived and designed the experiments: $\mathrm{T}$ Yaseen \& F Mabood, Performed the experiments: F Mabood, Analyzed the data: R Gul, KU Rehman \& N Akhtar, Contributed materials/ analysis/ tools: R Gul, KU Rehman \& N Akhtar, Wrote the paper: T Yaseen \& F Mabood.

\section{References}

1. Almagrabi OA \& Abdelmoneim TS (2012). Using of arbuscular mycorrhizal fungi to reduce the deficiency effect of phosphorus fertilization on maize plants (zea mays L.). Life Sci J 9(4): 16481654.

2. Smith SE \& Read DJ (2008). Mycorrhizal Symbiosis. 3rd edition Academic Press.

3. Cavagnaro TR (2008). The role of arbuscular mycorrhizas in improving plant zinc nutrition under low soil zinc concentrations: A review. Plant Soil 304: 315-325.

4. Clark RB \& Zeto SK (2000). Mineral acquisition by arbuscular mycorrhizal plants. J Plant Nutr 23: 867-902.

5. Gyaneshwar P, Kumar GN, Parekh LJ \& Poole PS (2002). Role of soil microorganisms in improving $\mathrm{P}$ nutrition of plants. Plant Soil 245: 83-93.

6. Feng G, FuSuoZh, XiaoLin L, Changyan T, Caixian T \& Zed R (2002). Uptake of 
nitrogen from indigenous soil pool by cotton plants inoculated with arbuscular mycorrhizal fungi. Commun. Soil Sci Plan Ana 33: 3825-3836.

7. Al-Karaki GN (2006). Nursery inoculation of tomato with arbuscular mycorrhizal fungi and subsequent performance under irrigation with saline water. Sci Hort 109: 1-7.

8. Karanika, ED, Voulgari OK, Mamolos AP, Alifragis DA \& Veresoglou DS (2008). Arbuscular mycorrhizal fungi in northern Greece and influence of soil resources on their Pedobiologia. Afri J Agri Res 409-418.

9. Cavagnaro TR, Jackson LE, Six J, Ferris H Goyal S, Asami D \& Scow KM (2006). Arbuscular mycorrhizas, microbial communities, nutrient availability and soil aggregates in organic tomato production. Plant Soil 282: 209-25.

10. Pasqualini D, Uhlmann A \& Stürmer SL (2007). Arbuscular mycorrhizal fungal communities influence growth and phosphorus concentration of woody plants species from the Atlantic rain forest in South Brazil. Forest Ecol Manage 245: 148-55.

11. Anselem A (2004). Herbs for healing pax herbals Edo State, Nigeria.

12. Shinwari ZK, Watanabe T, Rehman M \& Youshikawa T (2006). A pictorial guide to Medicinal Plants of Pakistan. Kohat University of Science \& Technology, Pakistan. 247.

13. Hussain J, Khan AL, Rehman N, Hamayun M, Shah T, Nisar, Bano T, Shinwari ZK \& Lee IJ (2009). Proximate and nutrient analysis of selected vegetable species: A case study of Karak Region Pakistan. Afr J Biotechnol 8(12): 2725-2729.

14. Pandey M, Abidi AB, Singh S \& Singh RP (2006). Nutritional Evaluation of
Leafy Vegetable Paratha. J Hum Ecol 19(2): 155-156.

15. Phillips JM \& Hayman DS (1970). Improved procedures for clearing roots and staining parasitic and vesicular arbuscular mycorrhizal fungus Glomus intraradices. Can Jour Bot 64: 17391749.

16. Giovannetti M \& Mosse B (1980). An evaluation of techniques for measuring VAM infection in roots. New Phytol 84: 489-500.

17. McLean EO (1982). Soil $\mathrm{pH}$ and lime requirement. In Page, A. L., R. H. Miller and D. R.Keeney (eds.) Methods of soil analysis. Part 2-Chemical and microbiological properties. (2nd Ed.). Agronomy 9: 199-223.

18. Black CA (1965). Methods of Soil Analysis Part II- Chemical and MicroBiological Properties.No. 9 Series Agronomy.American Society of Agronomy Inc Publishers, Medison, Wisconsin, USA.

19. Gee GW \& Bender JW (1986). Partical size analysis. In W.C. Black, Editor, Methods of soil analysis, Part 1. American society of Agronomy, Madson, Widconson.

20. Nelson DW \& Sommers LE (1882). Total Carbon, Organic carbon and organic matter. In: A.L. Pade., R.H. Miller and Keeneys (Eds). Method of soil analysis Part 2.Agronomy 9 AM. Soc Agric Mad W1 539-577.

21. Wei GT \& Wang HG (1991). Effect of vesicular-arbuscular mycorrhizal fungi on growth, nutrient uptake and synthesis of volatile oil in Schizonepeta tenuifolia Briq. Chin J Chin Mater Med 16(3): 139142.

22. Wei GT \& Wang HG (1989). Effects of VA mycorrhizal fungi on growth, nutrient uptake and effective compounds in Chinese medicinal herb Datura stramonium L. Sci Agr Sin 22(5): 56-61. 
23. Toussaint JP (2007) Investigating physiological changes in the aeria parts of AM plants: what do we know and where should we be heading? Mycorrhiza 17: 349-353.

24. Akiyama K \& Hayashi H (2002). Arbuscular mycorrhizal funguspromoted accumulation of two new triterpenoids in cucumber roots. Biosci Biotechnol Biochem 66(4): 762-769.

25. Chaudhary V, Kapoor R \& Bhatnagar AK (2008). Effectiveness of two arbuscular mycorrhizal fungi on concentrations of essential oil and artemisinin in three accessions of Artemisia annual. Appl Soil Ecol 40: 174-181.

26. Huang JH, Tan JF, Jie HK \& Zeng RS (2011). Effects of inoculating arbuscular mycorrhizal fungi on Artemisia annua growth and its officinal components. Chin J Appl Ecol 22(6): 1443-1449.

27. Sarwade PP, Chandanshive SS, Kanade MB \& Bhale U (2011). Diversity of Arbuscular Mycorrhizal (AM) Fungi in some common plants of Marathwada region. Inter Multidisci Res J 1(12): 1112.

28. Sharma BB \& Jha DK (2012). Arbuscular mycorrhiza dark septate fungal associations in medicinal and aromatic plants of Guwahati. $J$ Microbial Biotech Res 2(1): 212- 222.

29. Muthukumar T, Senthilkumar M, Rajangam M \& Udaiyan K (2006). Arbuscular mycorrhizal morphology and dark septate fungal associations in medicinal and aromatic plants of Western Ghats, Southern India. Mycorrhiza 17: 11-24.

30. Hildebrandt U, Janetta K, Ouziad F, Renne B, Nawrath K \& Bothe H (2001). Arbuscular mycorrhizal colonization of halophytes in Central European salt marshes. Mycorrhiza 10: 175-183.

31. Brown AM \& Bledsoe C (1996). Spatial and temporal dynamics of mycorrhizas in Jaumea carnosa, a tidal saltmarsh halophyte. J Ecol 84: 703-715.

32. Kahn AG (1974). The occurrence of mycorrhizas in halophytes, hydrophytes and xerophytes, and of Endogone spores in adjacent soils. J Gen Microbial 81: 714.

33. Mason E (1928). Note on the presence of mycorrhizae in the roots of salt-marsh plants. New Phytol 27:193-195.

34. Karagiannides N, Panou-Filotheou $\mathrm{H}$, Lazari D, Ipsilantis I \& Karagianidou C (2010). Essential oil contents and composition, nutrient and status of some aromatic and medicinal plants of northern Greece. Nat Prod Commn 5(5): 823-830.

35. Olfat K \& Jalil K (2012). Spore density and root colonization by arbuscular mycorrhizal fungi in some species in the northwest of Iran. Inter Res J App Basic Sci 3(5): 977-982.

36. Alejandra B, Norberto B, Noelia C, Florencia S \& Marta C (2014). Arbuscular mycorrhizal fungi in saline soils: Vertical distribution at different soil depth. Bra J Microb 45(2): 585-594. 